\author{
Paper do NAEA \\ Volume 1, Número 2, Edição/Série 484
}

\title{
As representações da paisagem do Pantanal a partir da obra musical do Grupo ACABA ${ }^{1}$
}

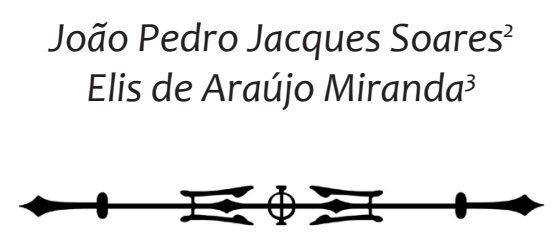

\section{RESUMO}

O objetivo do presente trabalho, nos apoiando na fenomenologia que orienta o pensamento da corrente da geografia humanista e cultural renovada, é estudar a relação entre ciência e arte, neste caso geografia e música. Para isso apreendemos as representações que um grupo artístico faz da paisagem de sua região, mais especificamente do Pantanal Mato-grossense, no Centro-Oeste do Brasil, a fim de estabelecer um quadro das representações da paisagem desta região geográfica. Percebendo assim seu mundo vivido, produzidos pelas experiências que exercem ao lugar que estão inseridos, carregando dessa forma sentido a paisagem que é representada pelos sujeitos que vivenciam o lugar e expressam suas vivências por meio das letras das músicas, dos instrumentos utilizados e das sonoridades criadas.

Palavras-chave: Representações. Música. Paisagem. Pantanal. Grupo ACABA.

\footnotetext{
1 Este trabalho foi elaborado a partir de pesquisa desenvolvida no âmbito do Programa de Bolsas de Iniciação Científica (PIBIC-CNPq) no período de 2017 a 2018 no Laboratório de Pesquisa Planejamento, Cultura e Representações Espaciais (LabCult), do Instituto de Ciências da Sociedade e Desenvolvimento Regional (ESR) da Universidade Federal Fluminense (UFF), Unidade de Campos dos Goytacazes.

2 Graduando em Geografia na UFF. Bolsista PIBIC CNPq-UFF no período de 2017 a 2018. E-mail: jpedro.jsoares@ gmail.com.

3 Geógrafa. Doutora em Planejamento Urbano e Regional. Coordenadora do LabCult e orientadora da pesquisa. E-mail: elismiranda@id.uff.br.
} 


\section{ABSTRACT}

The objective of this work, built upon the phenomenology that guides the current thinking of the renewed humanistic and cultural geography, is to study the relationship between Science and artistic expressions, and herein, between geography and music. For that, we apprehended the representations of an artistic group about the landscape of their region, more specifically of the Pantanal Mato-grossense (tropical wetland) in the Brazilian Midwest, in order to establish a picture of the landscape representations of this geographical region. Thus perceiving their lived world, produced by the experiences they exert to the place they are inserted in, hence bearing both meaning and landscape which is represented by the subjects who experience the place and express their livingness by means of their songs, their instruments and the sonority they create.

Key Words: Representations. Music. Landscape. Pantanal. Grupo ACABA. 


\section{INTRODUÇÃO}

A relação entre geografia e a música começa a ser estudada mais profundamente a partir do final da década de 1960, nos EUA, no contexto do desenvolvimento da escola de pensamento geográfico denominada Geografia Cultural. No Brasil essa linha de pesquisa ganha corpo trinta anos mais tarde, sendo a primeira tese defendida no Programa de Pós-Graduação em Geografia da UFRJ em 1991, por João Batista Ferreira de Mello, cujo título denominava-se: O Rio de Janeiro dos compositores da música popular brasileira - 1928/1991 - uma introdução à geografia humanística, sob a orientação de Roberto Lobato Corrêa. Incorpora-se como um sub-campo da corrente de pensamento denominada Geografia Cultural.

Essa corrente de pensamento passa atualmente por uma renovação epistemológica, atraindo novos elementos para seu campo de estudo. Essa renovação se deu a partir da década de 1970, fez com que os geógrafos, como Edward Relph, autor do livro Place and Placelessness (1976) e Yu-Fu Tuan, autor dos livros Topofilia (1972), Paisagem do Medo (2006) e O Espaço do Lugar (2015) buscassem suportes filosóficos para melhor amparar os estudos interdisciplinares entre geografia, cultura e arte. Do campo da fenomenologia, com influência de autores como Edmund Hursserl, MarleuPonty e Martin Heidegger propiciaram a constituição da corrente de pensamento denominada Geografia Humanista.

Dessa forma, buscamos estudar a relação entre a ciência geográfica e o campo das artes, a partir de uma orientação epistemológica fenomenológica. Para isso apreendemos as representações que o grupo musical ACABA elaborou sobre a paisagem da região do Pantanal Matogrossense. Busca-se as representações da paisagem que este grupo expressa nas letras e na sonoridade. Percebendo assim seu mundo vivido, produzidos pelas experiências que exercem ao lugar que estão inseridos, carregando dessa forma sentido a paisagem que é representada pelos sujeitos.

O Grupo musical ACABA foi criado no contexto cultural do Pantanal Sul-Matogrossense, (Imagens 1 e 2) no qual sua obra é composta por letras que apresentam descrições das paisagens dessa região, cantam sobre os hábitos do pantaneiro a partir de um projeto de pesquisa musical que tem como propósito divulgar a cultura do Pantanal a partir das letras das músicas e a partir da sonoridade, dos ritmos e de instrumentos próprios.

O Grupo ACABA, cujo nome acaba compõe uma sigla que expressa Associação dos Compositores Autônomos do Bairro Amambaí, representam a música regional de raiz de Mato Grosso do Sul, fundado em 1969, em Campo Grande, com o objetivo de pesquisar, desenvolver e divulgar o folclore 4 do antigo Estado de Mato Grosso e atual Mato Grosso do Sul.

As letras selecionadas expressam as percepções do Grupo sobre o lugar de onde vivem: os personagens, as formas de trabalho, da fauna e da flora, da cultura dos povos originários, da forma de transporte e meio ambiente. Todos esses aspectos são norteados por um elemento que percorre, modela e organiza toda a vida da região: a água.

Essas letras analisadas fazem parte de dois álbuns do Grupo ACABA, primeiro o Cantadores do Pantanal de 1979 e o Ultima cheia de 1984, ambos produzidos pelo selo independente Discos Marcus Pereira, grande influenciador da preservação da música popular brasileira.

4 O termo folclore é utilizado pelo grupo para designar a cultura do povo do Pantanal. 


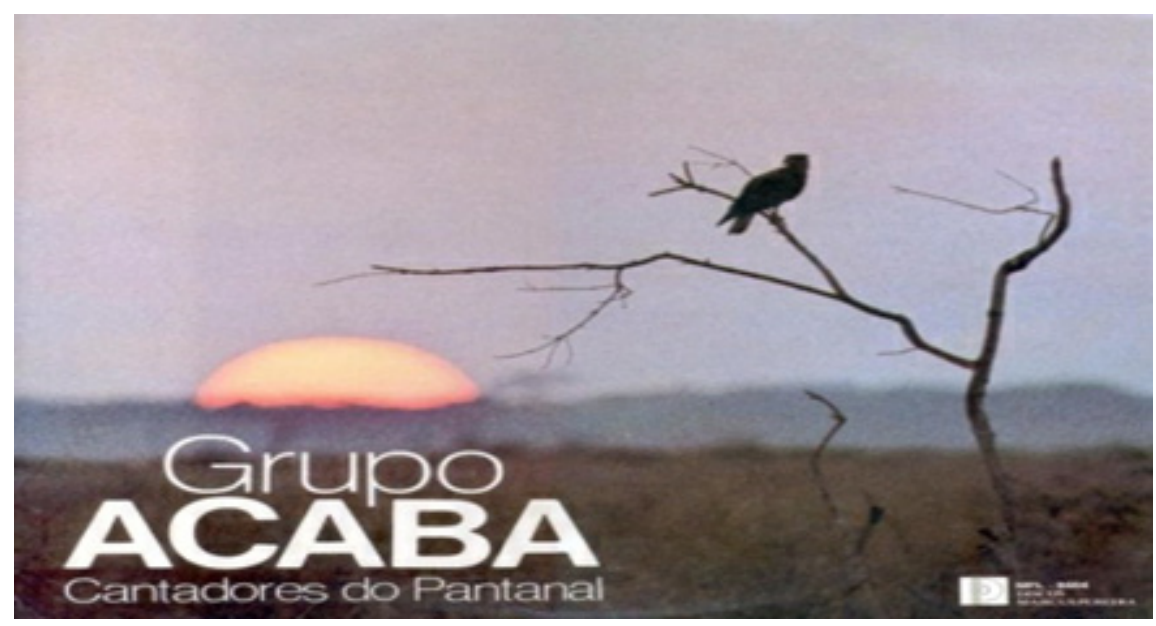

Imagem 1-Capa do disco Cantadores do Pantanal (1979)
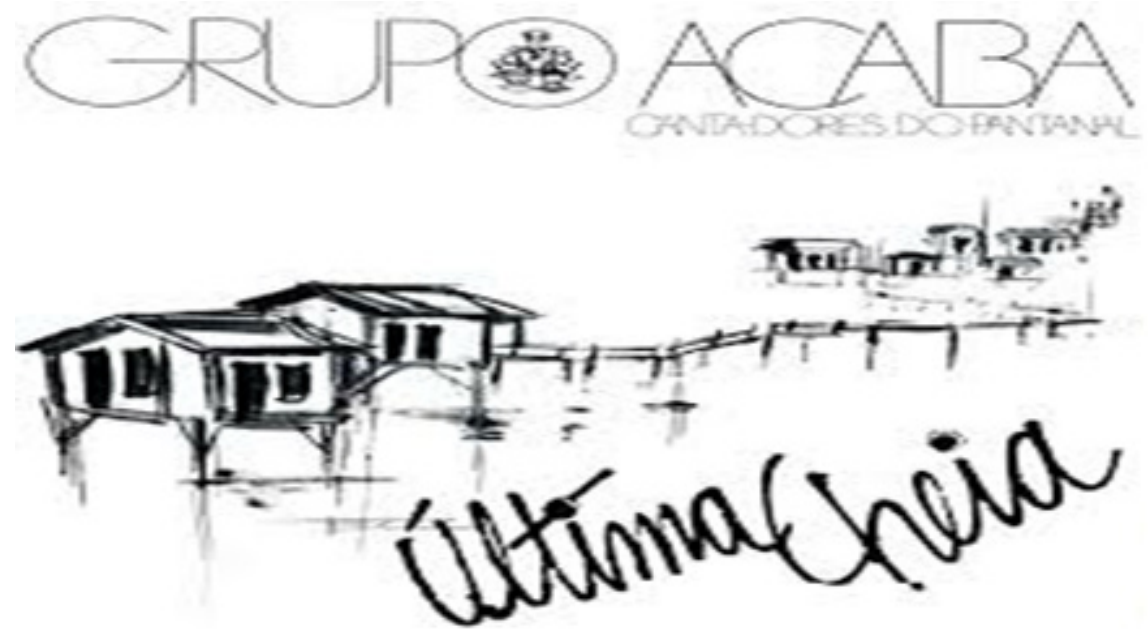

Imagem 2-Capa do disco Última cheia (1984)

A orientação metodológica segue em dois eixos: a) primeiro seguiu pela compreensão do método, da apreensão do campo teórico que envolve o conceito de paisagem e a sua relação com as artes e b) o segundo eixo esteve associado ao fazer científico a partir da apropriação do campo documental e empírico a partir da seleção dos álbuns e das letras e da análise das letras e das sonoridades que compõem a paisagem sonora do Pantanal.

O método fenomenológico que orienta a corrente de pensamento da geografia humanista e cultural foi o ponto de partida para compreendermos a paisagem para além do visível. Antes de iniciarmos a segunda etapa foi necessário o embasamento teórico e filosófico, a partir de leituras de autores Eric Dardel (1954), Edward Relph (1970) e Yi-Fu Tuan (1974; 1979), que se engajaram em buscar uma perspectiva fenomenológica para a geografia em seus trabalhos, bem como leituras de artigos que compõem os livros de organização de Roberto Lobato Corrêa e Zeni Rosendahl (NEPEC-UERJ), além da leitura de artigos publicados na revista Geograficidades. 
Já a segunda etapa consistiu em realizar levantamento e leituras de textos que tratam da relação entre música e geografia, no qual fazem parte o livro Geografia e Música: diálogos, organizado por Leandro Dozena (2016), artigos que tratam do desenvolvimento de estudos da relação entre a geografia e a música no mundo e mais especificamente no Brasil, dentre eles o de Castro (2009) e Panitz (2010; 2012), bem como de textos teóricos que orientam o entendimento sobre o conceito de paisagem no âmbito da geografia humanista e cultural, dos quais autores como: Augustin Berque (1998), Denis Cosgroove (1998;2000), Paul Claval(2004) e WeatherHolzer (1996), além de textos que trazem embasamento a respeito de paisagem sonora, com dois livros de Schaffer (1991; 2001), bem como o artigo de Torres e Kozel (2010). A leitura de textos que trouxeram um referencial sobre o pantanal, no qual estão presentes o livro de Mario César Leite (2003) e o de Carolina Joana da Silva e Joana A. Fernandes Silva (1995).

E assim seguimos para o levantamento das letras, sonoridades e histórias contadas pelo Grupo ACABA, bem como a audição de suas músicas, na busca de identificar as representações da paisagem e assim podermos elaborar um quadro da paisagem pantaneira.

Os resultados encontram-se organizados em 3 sessões do artigo a partir desta estrutura: a) Geografia e Música: mediação da paisagem; b) na revisão do conceito de paisagem no âmbito da geografia humanista-cultural; c) Leitura das Paisagens do Pantanal a partir das letras do Grupo Acaba.

\section{GEOGRAFIA E MÚSICA: MEDIAÇÃO DA PAISAGEM}

Trataremos brevemente da relação entre a música e a geografia, a qual tem seu auge na Universidade de Berkeley, EUA a partir do final da década de 1960, devido à renovação da geografia cultural. Trazendo também as principais referências desta relação aqui no Brasil a partir da década de 1990.

Talrelaçãoserámediadaapartirdo conceito depaisagem, no qual apreendemosas representações da paisagem do Pantanal a partir da obra musical do grupo ACABA, por isso não foi feita apenas a análise de suas letras, porém de toda sua sonoridade expressa nas músicas do referido grupo. A utilização do conceito de paisagem sonora se tornou fundamental para o presente estudo.

Esse item está dividido em três partes: o auge de estudos da relação entre a geografia e a música, seguido de uma breve linha histórica sobre o conceito de paisagem a partir da corrente do pensamento da geografia humanista e cultural, para então analisarmos o conceito de paisagem sonora segundo Schaffer (1991; 2001) a fim de propormos análises da sonoridade da paisagem a partir de uma expressão artística.

Os estudos envolvendo a relação entre a geografia e a música tornam-se mais consistentes na virada da década de 1970, quando a geografia cultural se renova. Essa transformação traz novos elementos que são incorporados aos estudos que abarcam espaço e cultura, portanto a música foi um dos aspectos que ilustra esse novo momento em que a geografia cultural iniciava, e dessa forma insere uma nova base epistemológica para as pesquisas, como nos diz Castro (2009):

As transformações que a geografia cultural sofreu a partir dos anos 70 trouxeram novas matrizes epistemológicas e metodológicas para a disciplina [...] Esse debate, além de permitir a inclusão de novos objetos de estudo ao 'repertório' da geografia cultural, permite novas acepções e abordagens a objetos que já eram de interesse da disciplina anteriormente. Os estudos geográficos sobre música, ou musicgeography, exemplificam muito bem esta situação (CASTRO, 2009, p.7). 
Esse campo de pesquisa foi inicialmente abraçado por autores norte-americanos que desempenharam um papel fundamental para o desenvolvimento dessa área. Dois artigos são fundamentais para a constituição e fortalecimento da mesma, o pioneiro de Peter Hugh Nash (1968) e um escrito dez anos mais tarde de George O. Carney (1978), logo em seguida diversos outros artigos vão sendo publicados, e os estudos sobre a música tomam força e se tornam um novo sub-campo dentro da geografia cultural. Outra autora muito importante para o crescimento desse campo é a cingapuriana Lili Kong (1995), que trouxe diversos elementos e uma valiosa contribuição crítica no que concerne aos trabalhos realizados anteriormente, como o questionamento de estudos que visavam somente uma classe elitista e não os personagens populares dos lugares e suas músicas: "A relativa indiferença dos geógrafos pela cultura popular (aí incluída a música popular) reflete a longa permanecia do foco cultural geográfico pela cultura de elite" (KONG, 2012, p. 130).

No Brasil ainda são poucos os trabalhos realizados, mas eles vem tomando força e vem cada vez mais sendo visível a presença desse tema. O estudo pioneiro foi a dissertação de mestrado de Mello (1991), na qual apresentava a cidade do Rio de Janeiro através dos compositores da MPB a partir de uma literatura musicada. "A abordagem humanista que se articula em torno das representações da paisagem e do lugar e a compreensão dos significados destas representações através da música são o cerne da maioria dos trabalhos desenvolvidos no Brasil" (PANITZ, 2013, p.7), no qual são influenciados pela renovação teórica de estudos de espaço e cultura.

Outros trabalhos são produzidos sobre diferentes perspectivas, existindo dessa forma uma certa heterogeneidade nos estudos. Panitz (2013) estabelece um quadro com quatro grandes temas elaborados: 1) Abordagem humanista que se articula em torno das representações da paisagem e do lugar e a compreensão dos significados através da música; 2) Compreensão das letras, da música e seu contexto social, cultura e ambiente, percebendo a identidade espacial, como espaços de referência identitária; 3) A música para compreender os usos do território (consumo, produção e atividade econômica) e 4) Música como ferramenta de reflexão de conceitos geográficos em sala de aula.

Um agente essencial para a formação e desenvolvimento desse sub-campo é o Núcleo de Estudos e Pesquisas sobre Espaço e Cultura (NEPEC), da UERJ, que foi um fomentador do debate das expressões artísticas culturais incorporadas pela geografia, no qual dois grandes nomes tem de ser reconhecidos: Roberto Lobato Corrêa e Zeni Rosendahl.

Sendo assim, a diversidade de interesses apresentada pela geografia brasileira, e a indiscutível riqueza musical do país, fazem deste campo de estudo um lugar fecundo para explorar o espaço geográfico em suas mais diversas abordagens e já tem oferecido, sem dúvidas, novos olhares para as relações entre espaço e cultura (PANITZ, 2013, p.7).

Fica claro a importância de cada vez mais se apoiar em estudos que trazem a reflexão que envolve a relação entre a geografia e a música. O Brasil é um locus privilegiado quando se trata de expressões musicais, o respeito que se tem aos cantadores de raiz, da música popular, a diversidade encontrada pelos cantos do país é nítida, a identidade regional, as representações dos lugares e da paisagem estão na "boca do povo", portanto há ainda muitos elementos a serem incorporados nessa área de pesquisa, e que ainda tem muito a se desenvolver.

Assim, buscando a relação entre a geografia e a música mediada pela paisagem é necessário que façamos uma breve linha histórica de tal conceito, bem como da corrente que orienta o estudo: a geografia cultural e humanista. 


\section{O CONCEITO DE PAISAGEM NO ÂMBITO DA GEOGRAFIA HUMANISTA-CULTURAL}

É essencial que compreendamos o conceito chave que guia o estudo: a paisagem, essa que será interpretada a partir da perspectiva da geografia humanista, orientada pelo método fenomenológico. É importante demonstrar de que forma se deu, em linhas gerais, o desenvolvimento do respectivo conceito para tal campo, bem como o próprio desenvolvimento da corrente da geografia humanista.

A paisagem enquanto categoria de análise para a geografia sofreu diversas mudanças, assim, recebeu diferentes significações pelos diferentes grupos que fundamentavam o pensamento geográfico.

Para Holzer (2012), os precedentes de uma abordagem humanista em geografia, no qual buscava em seus estudos uma análise objetiva e subjetiva da imaginação e ação dos sujeitos que fugiam do caráter cartesiano e positivista, se estabelecem mais precisamente na década de 1920. Portanto a geografia humanista se desenvolve a partir de duas bases que lhe dão sustentação, essas que são a geografia cultural e a geografia histórica, representadas por dois geógrafos que foram muito importantes para o aprimoramento desse campo de pesquisa, ambos de um contexto anglo-saxão, representantes da Escola de Berkeley. Dessa forma, Sauer (1925) propunha ao estudo a paisagem como:

(...)conceito síntese da geografia - deveria iniciar-se com o estabelecimento de um sistema critico delimitado pela fenomenologia da paisagem como método de estudo da relação entre o homem e o ambiente por ele formado e transformado em habitat, em paisagem cultural (SAUER apud HOLZER, 2012, p. 166).

Essas ideias levantadas por Sauer se disseminaram por todo os EUA e mundo, nos quais se desenvolveram muitos cursos de geografia cultural. Outro fator fundamental para a consolidação de uma geografia humanista foi a aproximação com a geografia histórica, cujo grande representante foi Wright (1947), também dos EUA, que trazia a ideia da fuga da geografia para além dos planos acadêmicos que se orientavam por análises objetivas. Nesse sentido, buscava-se a incorporação de analises subjetivas que estivessem para além de análises sistemáticas (WRIGHT apud HOLZER, 2012).

Em 1960 se tem o crescimento do domínio de uma área que se apresentava como base para análises de modelos matemáticos em estudos geográficos: a geografia quantitativa, bem como o surgimento da geografia comportamental. A geografia cultural, dessa forma, vinha perdendo força no meio acadêmico norte americano. Um ex-aluno de Sauer, Lowenthal, baseado nas ideias de Wright, formulou metodologias que fugissem de análises matemáticas, construindo um "projeto de ciência que abarcasse os vários modos de observação, o consciente e o inconsciente, o objetivo e o subjetivo, o fortuito e o deliberado, o literal e o esquemático" (HOLZER, 2012, p. 166).

A década de 1960 foi muito importante para a consolidação da geografia humanista, pois trouxe dois fatores que contribuíram para tal, um deles foi o encontro anual da American Association Geographers (AAG) (1965), quando um grande tema uniu as áreas de pesquisa até então distantes em geografia: a questão ambiental, e que serviu de elo para aproximações entre a geografia analítica com os geógrafos históricos e culturais. Outro fator muito essencial - esse que não representa mais somente um caráter interno à geografia - é a aparição dos movimentos de contracultura, nos EUA. Esse momento se torna muito importante na 
construção de uma ciência mais humana, pois já não era mais possível se fazer uma leitura de mundo baseada somente em modelos mecanicistas e operacionais.

Esse momento proporcionou o encontro de dois autores, Lowenthal, já citado, e Tuan, garantindo um novo rumo para a renovação radical da geografia cultural. Tuan (1961) se dedicava a estudos do "amor do homem pela natureza denominada de topofilia, a geografia se daria pelo estudo das vivências, que se expandem do lar para paisagens mais amplas, da paisagem humanizada para cenários mais selvagens" (HOLZER, 2012, p. 166).

A perspectiva aqui apresentada parte de uma ideia concebida a partir da década de 1970, quando as filosofias fenomenológicas geram um impacto significativo para a constituição do olhar sobre a geografia, e consequentemente ao conceito de paisagem. O primeiro autor a propor essa relação é Edward Relph (1970), trazendo a concepção de "desenvolver uma bagagem filosófica para as aproximações humanistas na geografia” (RELPH apud HOLZER, 2012, p. 169).

O argumento de Relph proporcionava duas questões importantes na utilização da fenomenologia pela geografia: "uma visão holística e unificadora da relação homem-natureza e a crítica ao cientificismo e ao positivismo" (HOLZER, 2012, p. 169). Outros autores seguiram tais concepções como Tuan (1972) e Buttimer (1974).

Para Buttimer (1974), a importância de se estabelecer a relação entre a geografia e a fenomenologia era a busca pela "totalidade do ser - percepção, pensamento, símbolos e ação -, o que se constata na prática, na qual se torna impossível delimitar claramente o que é sujeito e o que é objeto" (HOLZER, 2012, p. 169).

A geografia cultural se renova, com sua base epistemológica devidamente construída, bem como seu campo de interesse e sua orientação filosófica fenomenológica em relação às aproximações humanísticas. Dois pontos essenciais aparecem: o conceito de mundo vivido e o conceito de ser/estar no mundo, no qual na geografia se identifica com o conceito de lugar.

Todavia, é fundamental ressaltar a contribuição do livro intitulado: "O homem e a terra: natureza da realidade geográfica" de Eric Dardel. Escrito em 1952 e resgatado anos mais tarde, essa obra que traz uma bagagem fenomenológica existencialista influenciou diversos autores humanistas e,

definia o espaço, fenomenologicamente, como a conjunção de distâncias e de direções que, tendo como referência o corpo e o suporte onde ele se instala, construiria um espaço primitivo. A parir deste, seriam constituídas categorias espaciais, como a de lugar e de paisagem (HOLZER, 2012, p. 170).

Dardel (2011) afirma que "muito mais que uma justaposição de detalhes pitorescos, a paisagem é um conjunto, uma convergência, um momento vivido, uma ligação interna, uma impressão, que une todos elementos". A paisagem é um retrato da natureza social dos indivíduos e compreende um símbolo da existência do mesmo, logo: "A paisagem pressupõe uma presença do homem, mesmo lá onde toma forma de ausência. Ela fala de um mundo onde o homem realiza sua existência como presença circunspeta e atarefada" (DARDEL, 2011, p.32). Portanto, "Ela coloca em questão a totalidade do ser humano, suas ligações existenciais com a terra, ou se preferimos, sua geograficidade original: a terra como lugar, base e meio de sua realização" (DARDEL, 2011, p.31).

As bases da formação de uma geografia cultural humanística estavam sendo consolidadas e, em 1976, foi elaborado um manifesto no qual expressavam as suas propostas de 
pesquisa. Assim se tem a renovação da geografia cultural, na qual, para Tuan (1976), em seu "Humanisticgeography", o objetivo era fazer uma nova leitura de todos os temas da geografia. Construir conhecimento científico de modo crítico, procurando na filosofia um ponto de vista para a avaliação de fenômenos humanos (HOLZER, 2012).

A partir da década de 1980, autores como Agustin Berque e Denis Cosgrove vão trazer novas perspectivas para o estudo sobre a paisagem, se engajando em fazer uma leitura mais crítica a partir da geografia cultural renovada de cunho marxista. Berque (1984) busca a reflexão da paisagem enquanto marca e matriz, essa que se torna o cerne da nova geografia cultural, que se define como:

A paisagem é uma marca, pois expressa uma civilização, mas é também uma matriz, porque participa dos esquemas de percepção, de concepção e de ação ou seja, da cultura - que canalizam, em certo sentido, a relação de uma sociedade com o espaço e com a natureza e, portanto, a paisagem de seu ecúmeno. E assim, sucessivamente, por infinitos laços de codeterminação (BERQUE, 2012, p. 239).

Essa nova concepção se diferenciou da perspectiva da geografia clássica que trazia o ideal de que "paisagem resultava sempre no jogo de mecanismos físicos, biológicos e sociais. Sua análise não se detinha absolutamente sobre o sentido que ela teria para os homens" (CLAVAL, 2012, p. 264). "Portanto, agora, o geógrafo não estuda mais apenas a paisagem como realidade objetiva. Preocupa-se com a maneira como a paisagem está carregada de sentido, investida de afetividade por aqueles que vivem nela ou que a descobrem" (CLAVAL, 2012, p.265). Contudo:

em resumo: 1) a paisagem é plurimodal (passiva-ativa-potencial) como é plurimodal o sujeito para o qual a paisagem existe; e 2) a paisagem e o sujeito são cointegrados em um conjunto unitário, que se autoproduz e se autorreproduz (e, portanto se transforma, porque há sempre interferências com o exterior) [...] o jogo será de soma zero se a paisagem não tivesse nenhum sentido. [...]. Esse jogo impregnado de sentido é a cultura" (BERQUE, 2012, p. 240-241).

Assim, a paisagem é diretamente assimilada aos sujeitos que marcam suas referências a partir de sua vivencia no espaço geográfico que são permeadas pela cultura de cada grupo, no qual cada um a olha e a percebe de maneiras distintas e que a ela dão sentido. Para Cosgrove (2012):

A paisagem sempre esteve intimamente ligada, na geografia humana, com a cultura, com a ideia de formas visíveis sobre a superfície da Terra e com sua composição. A paisagem, de fato, é uma 'maneira de ver', uma maneira de compor e harmonizar o mundo externo em uma 'cena', uma unidade visual (COSGROVE, 2012, p.223).

"O mundo que o indivíduo percebe jamais é objetivamente dado" (CLAVAL, p. 262). Essa afirmativa caracteriza esse novo modo de pensar a paisagem, a busca pelos elementos subjetivos em que se colocam frente à frente o indivíduo e o objeto, o ponto de vista do observador para o meio que ele habita, só assim dessa relação que pode ser representada a paisagem, como ressalta Brunet apud Claval (2012):

aquilo que o olho abarca [...] de uma só olhadela, o campo do olhar. A paisagem é, portanto, uma aparência e uma representação [...]. Só é paisagem quando percebida. Alguns de seus elementos não aguardaram a humanidade para existir mas, se compõem uma paisagem, é sob a condição de serem olhados. Somente a representação os faz paisagem (BRUNET apud CLAVAL, 2012, p. 263).

Nessa perspectiva, cada cultura construirá valores ao longo do tempo, a partir da apropriação da natureza e dos elementos presentes no meio onde habita e transforma-os, que é expresso 
na paisagem. Ao ser representada por uma cultura, a paisagem deve ser entendida como um receptáculo de símbolos construídos pelos personagens de um lugar, que a transforma ao mesmo tempo em que são transformados.

Outros elementos vão sendo incorporados às ideias sobre o conceito de paisagem. Um desses elementos é a leitura da categoria de análise para além de um plano apenas visual: "tudo aquilo que a visão abarca". No entendimento de paisagem aqui abordado, esse conceito não se encaixa, pois somente a visão não é capaz de alcançar e expor todos os elementos físicos e simbólicos presentes na paisagem. Dito isso, entendemos que a leitura da paisagem não pode ficar restrita apenas ao olhar, ela tem que esta preenchida por todos os sentidos do corpo, bem como formas e movimento. Como nos fala Berque (2004):

De fato, o que está em causa não é somente a visão, mas todos os sentidos; não somente a percepção, mas todos os modos de relação do indivíduo com o mundo; enfim, não é somente o indivíduo, mas tudo aquilo pelo qual a sociedade o condiciona e o supera, isto é, a paisagem situa os indivíduos no seio de uma cultura, dando com isso um sentido à sua relação com o mundo (sentido que, naturalmente, nunca é exatamente o mesmo para cada indivíduo) (BERQUE, 2004, p. 87).

Dessa forma, fica clara a condição da paisagem enquanto norteadora dos indivíduos no âmago de sua cultura, criando dessa forma sentido na sua relação para com o mundo. Portanto, a partir do pensamento da paisagem para além de seu campo visual, o presente trabalho buscará elementos do conceito de soundscape (paisagem sonora).

Os sons estão em todos os lugares, eles se expressam a partir de diversos elementos do cotidiano; seja alguns mais percebidos na cidade, com seus ruídos advindos das grandes construções civis, do trânsito, das trocas de informações entre pessoas, dos comércios, etc., seja no campo, onde se percebe com mais facilidade os sons expressos pelos fenômenos da natureza como o som dos rios, ventos, bem como o som dos animais, etc. Cada cultura marca a paisagem de determinada maneira a partir de suas experiências com os lugares.

Dessa forma, todos esses sons advindos do ambiente podem ser denominados de paisagem sonora. O idealizador do termo foi Murray Schafer (2001) se refeindo à paisagem sonora como:

qualquer campo de estudo acústico. Podemos nos referir-nos a uma composição musical, a um programa de rádio ou mesmo a um ambiente acústico com paisagens sonoras. Podemos isolar um ambiente acústico como um campo de estudo, do mesmo modo que podemos estudar as características de uma determinada paisagem (SCHAFER, 2001, p. 23).

Por comportar todos os sons de um determinado lugar, a paisagem sonora pode conter sons de diferentes naturezas, como por exemplo: Os sons dos animais; Os sons dos fenômenos da natureza (vento, chuva, trovões, mar, etc.); Os sons advindos dos objetos construídos pelos seres humanos (meios de transporte, ferramentas de trabalho, aparelhos eletrodomésticos, etc.); Os sons dos seres humanos (falas, sotaques, ato de caminhar ou correr, as músicas, etc.); entre outros (KOZEL, TORRES, 2010, p.127).

A paisagem sonora, dessa forma, por ser toda a sonoridade dos ambientes, leva aos indivíduos sentimentos de identidade e de pertencimento aos lugares. A paisagem sonora é cultural, ela cria diferentes significados aos lugares para diferentes indivíduos ou grupo sociais.

agem direta e constantemente em seus moradores na contribuição à perpetuação das falas e sotaques, dos gostos musicais, e na evocação de paisagens do passado, o que reforça valores existentes em cada indivíduo, que pode contribuir para sua 
fixação em lugares distintos, e à criação do sentimento de pertencimento a eles, pelo fato de apresentarem sonoridades que concedem familiaridade na paisagem (KOZEL; TORRES, 2010, p. 125)

Um dos elementos que fazem parte da paisagem sonora é a música. "A música retrata a cultura e a memória do povo. É uma coleção de sons concebidos e produzidos por sucessivas operações de pessoas que ouvem bem que quando executada, integra-se à paisagem sonora tornando-se um de seus elementos" (SCHAFER, 1991, p. 187). A música se configura como um fator dos sons presentes em nosso cotidiano, ela pode nos contar sobre os lugares, nos trazendo referenciais da paisagem. A música se faz presente da paisagem sonora, podemos estabelecer diversos elementos que são característicos de uma determinada paisagem a partir de seus sons.

Assim o conceito de paisagem sonora nos auxiliara nas análises das músicas, pois nos guiará a fazer um quadro sonoro característico da região do Pantanal, como o som da água, dos animais, dos personagens presentes no lugar.

\section{LEITURA DAS PAISAGENS DO PANTANAL A PARTIR DAS LETRAS DO GRUPO ACABA}

Para esse tópico apresentaremos o contexto tanto do pantanal, quanto ao contexto cultural do Grupo ACABA. E para finalizar fizemos um levantamento de cinco questões fundamentais que estão presentes nas músicas do Grupo ACABA, e que fazem parte da vivência do pantaneiro e das características principais da região. Esses que são 1) $O$ trabalho (travessia de gados); 2) A diversidade de sua fauna e flora; 3) A cultura indígena da região; 4) A defesa pelo meio ambiente; 5) As formas de transporte (travessia de navios pelos grandes rios). Esses pontos destacamos como essenciais na obra do referido grupo e que analisaremos em seguida as letras em si, bem como a sua sonoridade que expressam aspectos fundamentais presentes na paisagem do Pantanal.

O Pantanal é moldado pelas águas que percorrem sobre a região; ela delimita, orienta, organiza as relações que ali se estabelecem: "A água é o elemento norteador das relações ali (Pantanal) desenvolvidas" (LEITE apud COSTA, 2003, p. 35). Diferente do que pode representar o nome, o Pantanal não é considerado um pântano, porém uma imensa área alagadiça, uma das maiores do mundo, o qual é recortado pelos grandes rios afluentes do rio Paraguai, incluindo o rio Cuiabá, que influenciam com suas diferentes características os dois momentos distintos e fundamentais para a configuração da região, esses que são: a época de enchente/cheia e a época de vazante/seca. "Neste fluxo e refluxo das águas o Pantanal respira, organiza-se, compõe-se e reorganiza-se em ritmos e sistemas de vida que se entrecruzam" (LEITE, 2003, p. 36).

O Pantanal é uma planície sedimentar, com área de $138.183 \mathrm{~km} 2$, que está inserida na região Centro Oeste do Brasil, na bacia do Alto Paraguai, entre as latitudes $14^{\circ} \mathrm{e} 23^{\circ} \mathrm{Sul}$ e longitudes $55^{\circ}$ e $60^{\circ}$ Oeste, possuindo distribuição nos estados de Mato Grosso e Mato Grosso do Sul, ocupando cerca de $4,2 \%$ do território nacional (CRISPIN; CARDOSO, 2004).

As músicas que buscamos levantar para o presente estudo têm a ver com as características existentes nessa região, dessa forma são representações que o Grupo ACABA fazem de seu meio, as marcas expressas na paisagem, como que os personagens desse lugar se organizam 
em torno desse elemento fundamental: a água. Nesse sentido, como nos diz Dardel (2011): "O espaço aquático é um espaço liquido. Torrente, riacho ou rio, ele corre, ele coloca em movimento o espaço. O rio é uma substância que rasteja, que serpenteia [...] Aágua corrente, porque é movimento e vida, aplaina o espaço". Portanto, se percebe a importância da água para o espaço Pantanal. Essa que irá nortear toda configuração da superfície pantaneira, desde as relações de trabalho, com as grandes travessias de gados pelas grandes extensões alagadas, as formas de transporte pelos grandes rios, bem como a apresentação da rica fauna e flora, no qual mais uma vez se tem a presença essencial da água que desenvolveu uma enorme biodiversidade na região. Temos também letras que expressam a luta dos povos indígenas da região, bem como protestos em defesa do meio ambiente.

O Pantanal e o homem pantaneiro são temas das músicas. As letras são todas composições do Grupo Acaba, e são elaboradas coletivamente ou individualmente, mas sempre por um dos membros do grupo, e descrevem o homem, a fauna e a flora, as alegrias das cores e as dores do pantaneiro, conforme dizem os integrantes do Grupo.

O Grupo com mais de cinquenta anos de história e grande atuante dos festivais universitários do Mato Grosso do Sul em 1970, mistura diversos elementos dos expoentes que surgiram não só do contexto do Mato Grosso do Sul, mas também das referências latinas, bem como a música estrangeira, como o próprio Moacir Lacerda aborda, em entrevista de estúdio para a Portal da Educativa em 2016, no qual o Grupo gravava a grande antologia musical com seu repertório de cinco décadas com grandes participações especiais. O nome do disco se chama: Pantanal - nascentes, rio e vertentes.

Nascentes porque são músicas que formaram nossa cultura, nossa base musical. Os rio são os grandes hits do Grupo ACABA e as vertentes são as saídas, as grandes vertentes. Dentre essa tendências temos muita coisa moderna, que sai do pantaneiro. O pantanal não tem limites. Dessa forma, invadimos a América do Sul e vamos até Beatles também. Não estamos circunscritos, o Pantanal é a pátria das águas, portanto é necessário beber de outras fontes, porém nunca esquecer as raízes (Entrevista de LACERDA, 2016).

O Grupo ACABA apresenta uma mescla de ritmos em suas músicas, no entanto mantendo um presente som advindo das características de raiz de sua terra. Todos esses elementos se farão presentes nas letras, melodias, compostas pelo Grupo.

Cantando o povo pantaneiro, desde suas raízes e como se constitui esse povo, "queimado pelo sol e molhados pela chuva": Aqui a análise se faz para além da letra em si, porém também dos diversos elementos sonoros que compõem o espaço Pantanal. 


\section{Vaca tucura, boi pantaneiro (Última cheia, 1984)}

"Grande curral

Cerca de carandá

águas profundas.

Cheiro de lodo

pedaço de chão

terra molhada.

É o boi que passa, que

berra, que muge. Que

nasce que cresce, que

vive que morre. Que

puxa carreta, move o

engenho. Faz da garapa
sair o melado
É vaca tucura, é o boi
pantaneiro. $\quad$ Eta!
boizinho safado. Pintado
e encantado. Em telas e
versos. Amarrado no
tronco. Horizonte
perdido. Grande curral
Cerca de carandá águas
profundas. Cheiro de
lodo pedaço de chão
terra molhada. Um

rebanho assustado. Olhando de lado. Bate no chão levanta poeira. Desfazendo o cheiro sangue vermelho. Do boi que morrera, tem couro no sol Sanfona e viola a cama vazia. O peão que grita boiada que passa É o berrante tocando é o boi que caminha. Nesta terra molhada."

Essa letra expressa as relações de trabalho - pecuária - presente na região do pantanal, como a utilização de animais como os bois e as vacas, as chamadas travessias que ocorrem na época de cheia, os boiadeiros em seus cavalos pantaneiros tem de atravessar o gado da parte baixa que fica alagada para as partes altas as atravessando-os de fazenda a fazenda, esse trabalho já ocorre a dezenas de anos e faz parte da cultura pantaneira.

Já no início da música podemos perceber qual será o elemento principal da mesma, trazendo a sonoridade dos mugidos de bois, dando um sentido de movimento com o chacoalhar dos instrumentos utilizados pelos boiadeiros para localizarem mais facilmente o gado, bem como o assoviar e o som do berrante, elementos característicos que servem na condução das travessias de milhares de cabeças de gado.

Podemos perceber a representação da paisagem que o grupo faz da realidade do boiadeiro, assim apresentada: "Grande curral, cerca de carandá, águas profundas cheiro de lodo, pedaço de chão, terra molhada”. O curral feito com as madeiras do carandá, planta da família das arecáceas, típica da região. Águas profundas ilustrando a forma que o lugar toma na época das grandes cheias, o cheiro do lodo, o pedaço de chão e a terra molhada, todos elementos característicos que são representados e percebidos por todos os sentidos do corpo humano, não somente a visão, porém o olfato e o tato, aspectos esses que estão imbricados na paisagem pantaneira.

"Um rebanho assustado, olhando de lado, bate no chão, levanta poeira, desfazendo o cheiro, sangue vermelho, do boi que morrera, tem couro no sol". Os riscos nessas travessias são variados, o sacrifício que o gado sofre tendo que atravessar milhares de quilômetros em uma superfície alagada é enorme, bem como os peões em seus cavalos pantaneiros, muitos dos bois não resistem e acabam morrendo, e ocorre a retirada do couro do animal para uso de vestimenta de proteção do homem pantaneiro.

"Sanfona e viola, a cama vazia, o peão que grita, boiada que passa, é o berrante tocando, é o boi que caminha, nesta terra molhada". Outros elementos são percebidos, como a cultura da moda de viola presente, o berrante que toca acionando e organizando a boiada que passa pela terra molhada.

Desse modo, o ciclo das águas ditava o tempo exato de levar os animais de uma região para outra devido às enchentes nos locais, como também evitava atoleiros 
de gado durante a passagem da comitiva nas estradas. Essas observações e informações traduziam um conhecimento empírico do peão de boiadeiro que vivia uma relação íntima com o mundo natural (ZANCARINI, p.26, 2013).

A letra analisada é uma representação do real, sobre o modo de vida do pantaneiro, no qual traz um elemento característico da cultura local, que são as travessias com cabeças de gados por milhares de quilômetros influenciados pelos aspectos físicos que fazem parte da região e são fundamentais para a constituição das atividades ali realizadas. É possível, a partir da música, compreender as ideias, os hábitos, as crenças e os valores culturais de um grupo num determinadolugar, elementos esses queestãosendo representados na paisagem que os circunda.

O entendimento sobre as representações do indivíduo e/ou grupo existe na extensão de uma cultura sobre uma paisagem específica, contudo, tal cultura não está fechada em si mesmo. "Paisagem é uma manifestação sensível de uma mediação" (BERQUE, 2012, p. 242). Ela traz, portanto, através dos sentidos, as características do meio que é o resultado da relação entre sociedade e natureza. Dessa forma, "cada paisagem é produto e produtora de cultura, possuindo todas formas, sentidos, cores, movimento, experenciados por todas as pessoas que se integram a ela" (TORRES; KOZEL, p. 124, 2010). Portanto só é paisagem quando percebida.

O estudo sobre a paisagem, dessa forma, deve ir além do campo apenas visual, devendo considerar seus aspectos subjetivos. Deve ser compreendida como um receptáculo de símbolos. Todas possuem significados simbólicos porque são o produto da apropriação e transformação do meio ambiente pelo homem. A paisagem é cointegrada aos sujeitos, a partir dos sentidos, das relações dos indivíduos com o mundo, situando o indivíduo no seio de uma cultura, dando sentido à sua relação com o mundo.

As representações sobre o Pantanal são a essência de suas experiências sobre o lugar, e na verdade, são as imbricações deles sobre o meio, refletindo assim sua cultura a partir das diversas relações dos mesmos com a paisagem que os cerca, recheada de símbolos, de memória e de história, que o vão influenciar em sua vivencia, sua identidade. Como percebido pela canção Pássaro Branco:

\section{Pássaro Branco (Última cheia, 1984)}

"Quantas penas brancas que se movimentam, nesse lago de lama, nessa lama sem pena. Essa pena tão branca enfeitou o meu chão. Decorou o meu céu, pintou minha planta. Ainda criança aprendi o caminho dos pântanos. Embora sem pena... Aprendi a voar, Aprendi a voar. Sua asa tão linda abraçou o espaço. Desenhou meu retrato pra ficar nessa terra. Desvendar o mistério da morte mais branca. Que perdeu sua cor nesse lago de lama. Nesse lago de lama, o homem se inflama. De tanto ter pena, perdeu a canção. Sua asa tão linda abraçou o espaço, meu retrato pra ficar nessa terra. Desvendar o mistério da morte mais branca. Que perdeu sua cor nesse lago de lama. Nesse lago de lama, o homem se infla/ma. De tanto ter pena, perdeu a canção."

O observador/compositor vai pela paisagem, participa dela, a paisagem o marca, e ele a leva consigo, sendo essa paisagem que é o pantanal torna-se a ele intrínseca, faz parte dele: "ainda criança aprendi o caminho dos pântanos" o sujeito se coloca parte da paisagem 
que ele observa, se transmuta ao lugar. Podendo perceber as representações que faz da paisagem pantaneira: "Quantas penas brancas que se movimentam, nesse lago de lama, nessa lama sem pena." A forma como descreve sobre a questão das aves que são elementos característicos da região, por sua grande biodiversidade fomentada pelas grandes áreas alagáveis que gerou um ambiente propicio para a formação dessa grande diversidade de espécies de animais e vegetação. Assim como a característica física do Pantanal: as suas cheias, de suas "lamas", se colocando como parte integrante do meio nos brinda: "Essa pena tão branca enfeitou o meu chão".

Dessa forma, a partir da letra desta canção podemos perceber o quanto a paisagem do lugar está representando a cultura do povo pantaneiro: vendo sua fauna, sua flora, suas formas, seus aspectos, suas características; esses símbolos expressos na paisagem irão formar identidade ao grupo. Percebemos: "ainda criança aprendi os caminhos do pântano [...] sua asa tão linda abraçou o espaço, desenhou meu retrato pra ficar nessa terra" fica claro a relação do homem a sua terra, que cria um laço profundo com o chão, com o meio, com sua paisagem.

Buscando uma leitura para além da letra, percebemos nessa música, características do lugar Pantanal no qual mediada pela sonoridade nos brinda com elementos como o som dos pássaros característicos da região, soados assim pelos instrumentos que trazem a sonoridade das aves.

O grupo ACABA em suas canções, mais do que as letras, explora misturas de elementos que constroem a música de forma a fazer com que quem escuta se desloque para tal região pantaneira. Essa é a busca que trazemos aqui, a paisagem para além de seu aspecto visual, trazendo em suas canções: o som de fenômenos da natureza como a chuva, o som dos pássaros e dos bois, bem como cânticos dos povos indígenas de sua terra, que eles cantam com grande afetividade e tristeza, assim como falam da importância e vivência desses povos, além de utilizarem de instrumentos de origem indígena que simbolizam ainda mais um carinho pelos povos primeiros de sua terra, expresso pela bela música: Kananciue, esse que é o Deus maior dos povos indígenas da região.

\section{Kananciuê (Cantadores do Pantanal, 1979)}

"AruanãEtô é lugar das máscaras, MastePurú é lugar dos homens, AruanâEtô é lugar das máscaras, MastePurú é lugar dos homens. Nasci na terra onde o sol se levanta. Com jenipapo urucum pintei meu corpo. Com rabo de canastra fiz flauta. Pra ter meu cantar Pesquei pirarucú com arupema e cipó de imbó. Mandioca braba, inhame e cará plantei. Pra alimentar meu corpo. AruanãEtô foi invadido. Meu colar, meu tacape, minhas armas. Não fazem mais sentido. Nada vive muito tempo. Só a terra e as montanhas. Vem ver o que resta do seu povo, Kananciuê. Vem Jurumá expulsar Anhanguera. Jaci, Tupã, filhos de Kananciuê. Ninguém quer mais a paz do que eu na caminhada final Cante comigo $\mathrm{O}$ seu canto. Grite comigo o meu grito. ArauanãEtôMastepurú, Kananciuê. ArauanãEtôMastepurú, Kananciuê. Tacape, cocar, mangaba, cajá. ArauanãEtôMastepurú, Kananciuê. Tacape, cocar, mangaba, cajá. ArauanãEtôMastepurú, Kananciuê. Tacape, cocar, mangaba, cajá. ArauanãEtôMastepurú, Kananciuê". 
A introdução da música já traz elementos sonoros perceptíveis do que ela vai nos dizer. Traz o canto dos povos originários da região, bem como a utilização de instrumentos típicos dos mesmos, fazendo a mescla entre o misterioso, o divino, bem como a luta, as batalhas pela terra, expressas sonoramente com sons de percussão proporcionando um ritmo de exaltação ao lugar, instrumentos de sopro que trazem a sonoridade das aves que se complementam e se faz uma unidade entre índio e natureza.

Podemos perceber assim, como dito, que paisagem é produto e produtora de cultura, pois ao se apropriar da natureza os povos indígenas refletem sua paisagem e constroem sua identidade sobre o lugar. Ao se utilizar do urucum para pintar-se, do cultivo da mandioca para o consumo, da transformação de plantas para a utilização tanto na caça, tanto para suas lutas e batalhas, bem como para instrumentos utilizados em suas canções, demonstram essa relação intrínseca dos homens pelo seu meio.

Indo além, a canção ainda traz um tom de tristeza ao dizer: "nada vive muito tempo, só as terras e as montanhas, vem ver o que resta do seu povo Kananciue". Essa triste realidade vivida por quem um dia foi "dono da terra" como o próprio grupo denomina, é uma denúncia e lamento contra a selvagem e pseudo-integração da civilização branca como eles mesmos comentam.

O Pantanal de Mato Grosso foi território povoado por inúmeros grupos indígenas (Paiguá, Guaikuru, Bororo e Guató) que lutaram intensamente contra colonizadores espanhóis e portugueses desde o século XVI. Alguns grupos sobreviveram à guerra contra eles travada, e estão atualmente ilhados em pequenas reservas: são eles os Bororo, os Kadiwéu (remanescentes dos Guaikuru) e os Guató (SILVA; SILVA, 1995).

\section{Ainda resta uma esperança (Cantadores do Pantanal, 1979)}

\begin{abstract}
"Quando encontrei minha velha canoa, junto a lagoa debaixo de um tingui, descendo o rio fiquei desolado, tudo mudado meu sertão que eu conheci olhei pro céu e vi um binguá sozinho, longe do ninho, a voar cantando assim: oh Deus sustenta a esperança que ainda resta, fazei crescer a floresta pra salvar meu taquari. Uma tristeza invadiu meu peito,
\end{abstract}

vendo o defeito que alagou meu rico chão, pois destruíram ao redor, as matas, terras cavadas, erosão. Olhei pra margem, lá no binguazeiro, um colheiro que pousou cantava assim: (refrão). Desmatamento vem secar as fontes, imensas pontes de areia logo eu vi, nas águas rasas, é triste a cena nessas em terras em que nasci, a batueira devagar vagou, pousou na proa e olhou cantando assim: (refrão). Parei meu remo e chorei criança na esperança de tudo inundar ali, secar meus olhos mas salvar meu rio, que doentio vai correndo para o fim, na ânsia louca de fazer voltar a vida, minha voz sentida ecoou assim (refrão)."

Nessa letra percebemos a leitura da paisagem feita pelo personagem que está vivenciando seu lugar, percebendo a sua "velha canoa" elemento essencial de meio de transporte sobre a vasta área alagadiça, no qual se encontrava sob um tingui, típica flor do cerrado. Ele percorre por essa paisagem, "descendo o rio fiquei desolado, tudo mudado meu sertão que eu conheci" nesse ponto canta com saudosismo lembrando as belezas de sua terra, agora em tom de tristeza canta lamentando que ela já não é mais a mesma. A paisagem passa do campo visual, das lembranças do que foi visto, de como era o pantanal, para 
o campo do sentir, do sentimento das mudanças ocorridas naquele espaço, a paisagem que foi modificada por agentes externos. "Uma tristeza invadiu meu peito, vendo o defeito que alagou meu rico chão, pois destruíram ao redor, as matas, terras cavadas, erosão" [...] "Desmatamento vem secar as fontes, imensas pontes de areia logo eu vi, nas águas rasas, é triste a cena nessas em terras em que nasci". Diversos elementos são aqui considerados e percebidos, que no qual fizeram a paisagem se transformar e não mais ser aquela lembrança afetiva que ele trazia em suas lembranças. Não mais se tem a imensa superfície alagada, agora são "águas rasas, pontes de areia e fontes secas."

O sujeito se torna tão cointegrado à paisagem que se percebe como um só, como expresso nessa passagem: "Parei meu remo e chorei criança na esperança de tudo inundar ali, secar meus olhos mas salvar meu rio, que doentio vai correndo para o fim, na ânsia louca de fazer voltar a vida, minha voz sentida ecoou assim". Nesse sentido, a percepção do espaço do pantanal é carregada de significados, a paisagem como receptáculo de símbolos. "Os pantaneiros reconhecem a importância do regime de cheias e do ritmo das águas para a renovação da vida no Pantanal e para a preservação de seus ecossistemas"'(SILVA; SILVA, 1995).

\section{Fernando Vieira (Última cheia, 1984)}

$\begin{array}{ll}\text { "Porto Esperança, porto } & \text { maletas, gente de } \\ \text { da manga, e vai } & \text { muletas, redes } \\ \text { Corumbá a Cuiabá. A } & \text { estendidas no porão, o } \\ \text { prancha encosta no } & \text { cheiro da comida no } \\ \text { barranco é hora de partir } & \text { andar de cima, chegando } \\ \text { cantando, sacos e gostoso, no olhar }\end{array}$
molhado da criança. Avistando o dedo de São Gonçalo, três dias antes de chegar. La vai Fernando Vieira subindo o rio Paraguai. Nesta rota de aventuras, eu e meu pai, minha mãe, meu irmão. Via bois, melancias, canoas com rapaduras, na cheia do nosso chão".

Fernando Vieira foi um grande barco que fazia o transporte tanto de pessoas quanto de mercadorias, fazendo a ligação entre Porto Esperança, distrito de Corumbá, Mato Grosso do Sul, a Cuiabá, capital do Mato Grosso, pelo rio Paraguai. A estação ferroviária de Porto Esperança foi muito importante na época, o trem carregado de pessoas e cargas fazia a integração transporte ferroviário com o transporte fluvial. A hidrografia foi um fator condicionante no funcionamento e organização do transporte da região.

$\mathrm{Na}$ letra, o compositor/personagem descreve a saga das pessoas que viajam no barco, observando a configuração do mesmo: "sacos e maletas, gente de muletas, redes estendidas no porão". A partir de dois sentidos do corpo humano, o narrador relembra suas memórias afetivas: "o cheiro da comida no andar de cima, chegando gostoso, no olhar molhado da criança”, a paisagem permeada pelos sentidos que quando sentidas captam a memória e retornam os laços afetivos em torno de determinado recorte espacial.

E assim segue o Fernando Vieira deslizando sobre o Rio Paraguai, onde o observador ainda consegue perceber algumas das características da região de um ponto de vista, que é o de dentro do barco: "Via bois, melancias, canoas com rapaduras, na cheia do nosso chão". 


\section{CONSIDERAÇÕES FINAIS}

O grupo ACABA em suas canções, mais do que as letras, explorando uma mescla de elementos que constroem a música, de forma a fazer com que quem escuta se desloque para tal região pantaneira. Essa é a busca que trouxemos aqui: a paisagem em seus mais variados aspectos percebidos aqui pelas músicas do Grupo ACABA: o som de fenômenos da natureza como a chuva, o som dos pássaros e dos bois, cânticos dos povos indígenas de sua terra, todos esses elementos característicos da região, expressos na paisagem.

A fenomenologia é um aporte filosófico fundamental para quem busca uma análise mais humana, cultural para estudos sobre a espacialidade. A paisagem enquanto conceito chave do estudo nos guiou de forma natural a se fazer a leitura da região pantaneira. Esses elementos todos em sintonia mostraram que a música e seus personagens são caminhos essenciais para o estudo da relação entre a natureza e o homem, entre o meio e o indivíduo, entre os espaços e a sociedade.

Nesse sentido, evidenciamos que é exequível a leitura da paisagem a partir de uma expressão artística. As representações que o grupo apresenta em suas canções são fundamentais para o estudo do conceito de paisagem para a geografia, a forma simples como descrevem a região pantaneira, a cultura dos personagens de lá, a configuração do espaço modelado pelas grandes cheias, a importância da água para os indivíduos, todos esses aspectos que estão presentes nas letras e que são expressos na paisagem, ou seja, são as representações que o Grupo ACABA faz sobre o a paisagem pantaneira. 


\section{REFERÊNCIAS BIBLIOGRÁFICAS}

BERQUE, A. Paisagem-marca, paisagem-matriz: elementos da problemática para uma geografia cultural. In: CORRÊA, R. L.; ROSENDAHL, Z. (Orgs.). Geografia cultural: uma antologia. Rio de Janeiro: EdUERJ, 2012. p. 239-243.

CABRAL, L. O.; BUSS, M. D. A paisagem como campo de visibilidade e significação: um estudo de caso. Espaço e Cultura, UERJ. RJ. N. 13, p. 47-62, jan/jun, 2012.

CASTRO, D. Geografia e música: a dupla face de uma relação. Espaço e Cultura, UERJ, RJ, N. 26, P. 7-18, JUL./DEZ. DE 2009.

CLAVAL, P. A paisagem dos geógrafos. In: CORRÊA, R. L.; ROSENDAHL, Z. (Orgs.). Geografia cultural: uma antologia. Rio de Janeiro: EdUERJ, 2012. p. 245-275.

COSGROVE, D. A geografia está em toda parte: cultura e simbolismo nas paisagens humanas. In: CORREAA, R. L.; ROSENDAHL, Z. (Orgs.). Geografia cultural: uma antologia (1). Rio de Janeiro: EdUERJ, 2012. P. 219-238.

DARDEL, E. O Homem e a Terra: natureza da realidade geográfica. (Tradução WertherWolzer). São Paulo: Perspectiva, 2011.

HOLZER, W. A geografia humanista: uma revisão. In: CORRÊA, R. L.; ROSENDAHL, Z. (Orgs.). Geografia cultural: uma antologia. Rio de Janeiro: EdUERJ, 2012. p. 165-178.

KONG, L. Música regional nas análises geográficas. In: CORRÊA, R. L.; ROSENDAHL, Z. (Orgs.). Cinema, música e espaço. Rio de Janeiro: EDUERJ. p. 129-175, 2009.

LEITE, M. C. S. Águas encantadas de Chacororé: natureza, cultura, paisagens e mitos do Pantanal. Cuiabá: Cathedral Unicen Publicações, 2003.

SCHAFER, R. M. A afinação do mundo: uma exploração pioneira pela história passada e pelo atual estado do mais negligenciado do nosso ambiente: a paisagem sonora. Trad. Marisa TrechFonterrada. São Paulo: Editora UNESP, 2001.

PANITZ, L. Por uma geografia da música: um panorama mundial e vinte anos de pesquisas no Brasil. Instituto de Geociências, Programa de PósGraduação em Geografia, Universidade Federal do Rio Grande do Sul, Porto Alegre, RS, Brasil, 2012.

TORRES, M. A.; KOZEL, S. Paisagens sonoras: possíveis caminhos aos estudos culturais em geografia. Raega-O Espaço Geográfico em Análise, v. 20, 2010.

ZANCARINI, N. S. Estrada Boiadeira, sua história, seus peões e comitivas: do sul de Mato Grosso ao Noroeste paulista (1915 a 1940). Universidade Federal da Grande Dourados, 2013. 


\section{Discografia do Grupo ACABA}

\section{Álbuns}

Cantadores do Pantanal (1979)

https://www.youtube.com/watch?v=B804-UMnwY8\&t=541s

A Última Cheia (1984)

https://www.youtube.com/watch?v=vKY7WfMpPZc

\section{Músicas analisadas}

Pássaro branco

Vaca tucura, boi pantaneiro

Kananciuê

Fernando Vieira

Ainda resta uma esperança 